\title{
Low Liver Density Is Linked to Cardiovascular Comorbidity in COPD: An ECLIPSE Cohort Analysis
}

This article was published in the following Dove Press journal:

International Journal of Chronic Obstructive Pulmonary Disease

\section{Damien Viglino $\mathbb{D}^{1,2, *}$ \\ Mickaël Martin',* \\ Natalie Almeras (1D) \\ Jean-Pierre Després' \\ Harvey O Coxson $\mathbb{D}^{3}$ \\ Jean-Louis Pépin ${ }^{2}$ \\ Isabelle Vivodtzev (iD ${ }^{2}$ \\ François Maltais ${ }^{1}{ }^{1}$ \\ On behalf of the Evaluation of COPD Longitudinally to Identify Predictive \\ Surrogate Endpoints \\ (ECLIPSE) investigators}

'Centre de Recherche, Institut Universitaire de Cardiologie et de Pneumologie de Québec-Université Laval, Québec, Canada; ${ }^{2}$ Hypoxia Pathophysiology Laboratory INSERM U I042, Grenoble Alpes University Hospital, Grenoble, France; ${ }^{3}$ Radiology, University of British Columbia, Vancouver, British Columbia, Canada

*These authors contributed equally to this work
Correspondence: Damien Viglino Centre de Recherche Institut Universitaire de Cardiologie et de Pneumologie de Québec, 2725 Chemin Sainte-Foy, Québec, QC GIV 4G5, Canada

Tel + I 4l865687| I

Email damien.viglino. I@ulaval.ca

\begin{abstract}
Purpose: Fatty liver disease is associated with cardiometabolic disorders and represents a potential key comorbidity in Chronic Obstructive Pulmonary Disease (COPD). Some intermediary mechanisms of fatty liver disease (including its histological component steatosis) include tissue hypoxia, low-grade inflammation and oxidative stress that are key features of COPD. Despite these shared physiological pathways, the effect of COPD on the prevalence of hepatic steatosis, and the association between hepatic steatosis and comorbidities in this population remain unclear. Liver density measured by computed tomography (CT)-scan is a non-invasive surrogate of fat infiltration, with lower liver densities reflecting more fat infiltration and a liver density of 40 Hounsfield Units (HU) corresponding to a severe $30 \%$ fat infiltration.
\end{abstract}

Patients and Methods: We took advantage of the international cohort ECLIPSE in which non-enhanced chest CT-scans were obtained in 1554 patients with COPD and 387 healthy controls to analyse the liver density at T12-L1.

Results: The distribution of liver density was similar and the prevalence of severe steatosis (density $<40 \mathrm{HU}$ ) was not different $(4.7 \%$ vs $5.2 \%$, p $=0.7)$ between COPD and controls. In patients with COPD, the lowest liver density quartile was associated, after age and sex adjustment, with coronary artery disease $\left(\mathrm{OR}_{\mathrm{a}}=1.59,95 \% \mathrm{CI} 1.12\right.$ to 2.24$)$ and stroke $\left(\mathrm{OR}_{\mathrm{a}}=2.20,95 \%\right.$ CI 1.07 to 4.50 ), in comparison with the highest liver density quartile.

Conclusion: The present data indicate that a low liver density emerged as a predictor of cardiovascular comorbidities in the COPD population. However, the distribution of liver density and the prevalence of severe steatosis were similar in patients with COPD and control subjects.

Keywords: chronic obstructive pulmonary disease, liver density, steatosis, fatty liver disease, chest CT-scan, cardiovascular comorbidity, ECLIPSE cohort

\section{Introduction}

Chronic obstructive pulmonary disease (COPD) is an independent risk factor for multiple comorbidities such as diabetes, coronary artery disease and hypertension. ${ }^{1,2}$ These comorbidities, which are associated with obesity, are a major cause of mortality in this population, particularly in mild to moderate COPD. ${ }^{3-5}$ Studies report an increasing proportion of obese COPD patients, leading to major metabolic disorders. ${ }^{6}$ The liver regulates multiple inflammatory pathways and free-fatty acid transportation and is particularly sensitive to ectopic fat deposition causing Fatty Liver Disease (FLD). ${ }^{7}$ The increased risk of cardiovascular disease in subjects with this liver disorder is also well documented. ${ }^{8-10}$ Main intermediary mechanisms of FLD (and its histological component steatosis) include insulin resistance, metabolic syndrome ${ }^{11}$ and some key 
features of COPD as reduced physical activity, ${ }^{12}$ low-grade inflammation, oxidative stress and hypoxia. ${ }^{13,14}$ Although hepatic steatosis is a continuous process, severe fat infiltration is considered to be present when $33 \%$ or more of liver tissue on a biopsy is infiltrated by fat (stage 2-3 in the steatosis grade of the NAFLD activity score). ${ }^{15}$ Liver density measured by computed tomography (CT) scan is a non-invasive surrogate of fat infiltration, with lower liver densities reflecting more fat infiltration and a liver density of 40 Hounsfield Units (HU) corresponding to a severe $30 \%$ fatty infiltration. ${ }^{16-18}$ Chest CTs are often available in patients with COPD and allow the assessment of the liver density in most of the cases, representing a potential «add-on» for clinicians wanting to avert comorbidities. We used the Evaluation of COPD Longitudinally to Identify Predictive Surrogate Endpoints (ECLIPSE) cohort to document the prevalence of fatty liver infiltration in patients with COPD in comparison with healthy controls, and to explore, in the COPD population, the association with major cardiovascular comorbidities collected in ECLIPSE.

\section{Materials and Methods}

\section{Population}

The multicenter, longitudinal ECLIPSE cohort study (Clinicaltrials.gov NCT00292552) was conducted to identify surrogate markers of COPD progression. ${ }^{19} 2164$ current or ex-smokers ( $\geq 10$ pack-years) with Global Initiative for Chronic Obstructive Lung Disease (GOLD) stage 2 to 4 and 582 smokers or never smokers with normal lung function who served as controls were recruited from 12 countries. $^{20,21}$ Patients' characteristics, blood samples and pulmonary function tests were obtained at baseline. Chest CT-scan was performed on all participants with the following protocol: $120-\mathrm{kV}$ peak, $40 \mathrm{~mA}$, and $1.00-$ or $1.25-\mathrm{mm}$ slice thickness, at full inspiration. All subjects on whom a valid CT-scan slice at T12-L1 was obtained, to assess liver mean CT attenuation, were included. Comorbidities and medical history were recorded at baseline with standardized questionnaires. ${ }^{19}$

\section{Liver Density Assessment}

Liver density was quantified by measuring mean organ attenuation in Hounsfield unit (HU) by the same investigator using the body composition analysis platform of the Institut universitaire de cardiologie et de pneumologie de Québec and a validated image analysis software (Slice-O-Matic, Tomovision, Montréal, Québec, Canada) according to standardized techniques. ${ }^{22,23}$ A standardized segmentation protocol was followed by the evaluator consisting in using an automated segmentation tool to identify the liver perimeter (Figure 1) and then manually remove all potential artefact such as the gall blatter or the portal vein. To ensure validity, a sample of all segmented images were randomly selected and redone by the same evaluator to assess for intra-observer variation. A second imaging expert segmented the same sample to evaluate inter-observer variation, showing an excellent inter-observer validity (Inter-Class Coefficient 0.98 , mean absolute difference $0.96 \mathrm{HU}$, mean relative difference $1.01 \%$ ).

\section{Statistical Analysis}

We compared the prevalence of severe steatosis (liver density $<40 \mathrm{HU}$ ) in COPD and controls using chi-square statistics. To document the association between liver density and cardiovascular comorbidities in COPD, patients with COPD were divided into quartiles of liver density. The quartiles 1 (lowest density, steatosis) and 4 (highest density, no steatosis, reference) were compared with logistic regression in order to evaluate the association (odds ratio) with coronary disease (CAD), diabetes, heart failure, hypertension and stroke. Unadjusted odds ratio (OR), age and sex adjusted OR $\left(\mathrm{OR}_{\mathrm{a}}\right)$ and age, sex and body mass index (BMI) adjusted $\mathrm{OR}$ $\left(\mathrm{OR}_{\mathrm{ab}}\right)$ were sequentially calculated. Available inflammatory markers were compared between quartiles using ANCOVA. All statistical analyses were performed using SAS 9.4 software (SAS Institute, Cary, NC, USA). A p-value $<0.05$ was considered as significant.

\section{Results}

\section{Population and Liver Attenuation Between COPD and Controls}

We retrieved 1941 patients (1554 COPD and 387 controls) for whom a CT slice at T12-L1 could be analysed for liver attenuation (Table 1). Patients with COPD were older ( $64 \pm 7$ years vs $55 \pm 9$ years; $p<0.001)$ and the proportion of men was greater

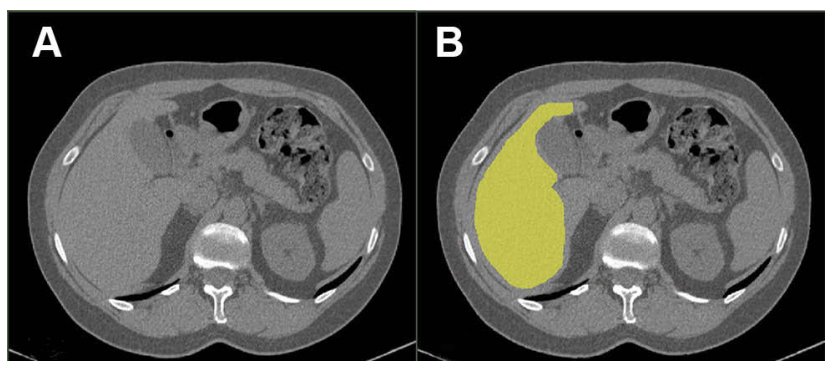

Figure I Example of a computed tomography slice before (Panel A) and after segmentation (Panel B). 
$(61 \%$ vs $57 \% ; \mathrm{p}<0.001)$ than in controls. BMI was slightly but significantly lower in patients with COPD $\left(26.1 \pm 5.2 \mathrm{~kg} / \mathrm{m}^{2}\right.$ in COPD vs $26.6 \pm 4.7 \mathrm{~kg} / \mathrm{m}^{2}$ in controls; $\mathrm{p}=0.046$ ). All considered cardiovascular comorbidities were significantly more prevalent in patients with COPD. The proportion of subjects with severe liver steatosis $(<40 \mathrm{HU})$ was not different between COPD and controls ( $4.7 \%$ vs $5.2 \%$, respectively, $\mathrm{p}=0.7)$. The distribution in hepatic densities (Figure 2) was similar between groups ( $\mathrm{p}>0.05$ for all comparisons).

\section{Association with Cardiovascular Comorbidities and Cytokines Levels}

The characteristics of the COPD population by quartile of liver density are presented in Table 2. In the COPD population, compared to the reference quartile (mean attenuation $68 \mathrm{HU}$ ),

Table I Characteristics of Patients with COPD and Control Subjects

\begin{tabular}{|c|c|c|c|}
\hline & $\begin{array}{l}\text { COPD } \\
(n=1554)\end{array}$ & $\begin{array}{l}\text { Controls } \\
(n=387)\end{array}$ & $p$ value $^{\dagger}$ \\
\hline $\begin{array}{l}\text { Age (years) } \\
\text { BMI }\left(\mathrm{kg} / \mathrm{m}^{2}\right) \\
\text { Liver attenuation }(\mathrm{HU}) \\
\text { Male, } \mathrm{n}(\%)\end{array}$ & $\begin{array}{l}63.6(0.2) \\
26.1(0.1) \\
58.7(9.2) \\
948(61)\end{array}$ & $\begin{array}{l}55.0(0.5) \\
26.6(0.2) \\
58.9(9.0) \\
174(45)\end{array}$ & $\begin{array}{l}<0.001 \\
0.04 \\
0.61 \\
<0.001\end{array}$ \\
\hline $\begin{array}{l}\text { Smoking status } \\
\text { Current smokers, n (\%) } \\
\text { Former smokers, n (\%) } \\
\text { Never smokers, n (\%) } \\
\text { Pack/year }\end{array}$ & $\begin{array}{l}575(37.0) \\
995(64.0) \\
- \\
48.4(0.7)\end{array}$ & $\begin{array}{l}139(36) \\
93(24.0) \\
155(40.1) \\
18.3(1.1)\end{array}$ & $\begin{array}{l}<0.001 \\
<0.001\end{array}$ \\
\hline 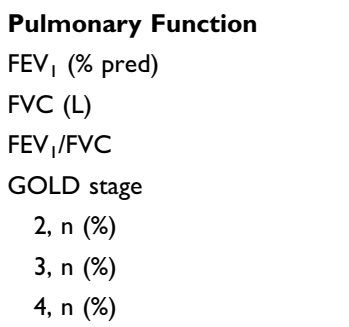 & $\begin{array}{l}43.5(0.4) \\
2.77(0.02) \\
0.44(0.01) \\
663(42.7) \\
675(43.4) \\
216(13.9)\end{array}$ & $\begin{array}{l}108.0(0.7) \\
4.15(0.05) \\
0.77(0.01)\end{array}$ & $\begin{array}{l}<0.001 \\
<0.001 \\
<0.001\end{array}$ \\
\hline $\begin{array}{l}\text { Clinical variables } \\
\text { SGRQ total score } \\
\text { Hypertension, n (\%) } \\
\text { Diabetes, n (\%) } \\
\text { Coronary artery disease, n (\%) } \\
\text { Heart failure, n (\%) } \\
\text { Stroke, n (\%) }\end{array}$ & $\begin{array}{l}49.2(0.5) \\
595(38.3) \\
138(8.9) \\
36 \mid(23.2) \\
90(5.8) \\
59(3.8)\end{array}$ & $\begin{array}{l}7.5(0.6) \\
23.0(5.9) \\
5.5(1.4) \\
39(10.0) \\
3(0.8) \\
6(1.6)\end{array}$ & $\begin{array}{l}<0.001 \\
<0.001 \\
0.03 \\
<0.001 \\
<0.001 \\
0.03\end{array}$ \\
\hline Death during follow-up (n) & $139(8.9)$ & $19(4.9)$ & $<0.001$ \\
\hline
\end{tabular}

Notes: Values are mean (SE) unless stated otherwise. ${ }^{\dagger} p$-value for $\mathrm{Chi}^{2}$ or Student's $t$-test. Significant $\mathrm{p}$-values are shown in bold.

Abbreviations: $\mathrm{HU}$, Hounsfield Units; BMI, body mass index; $\mathrm{FEV}_{1}$, forced expiratory volume in I s; FVC, forced vital capacity; GOLD, global initiative for chronic Obstructive Lung Disease (severity scale); SGRQ, St-George Respiratory Questionnaire.

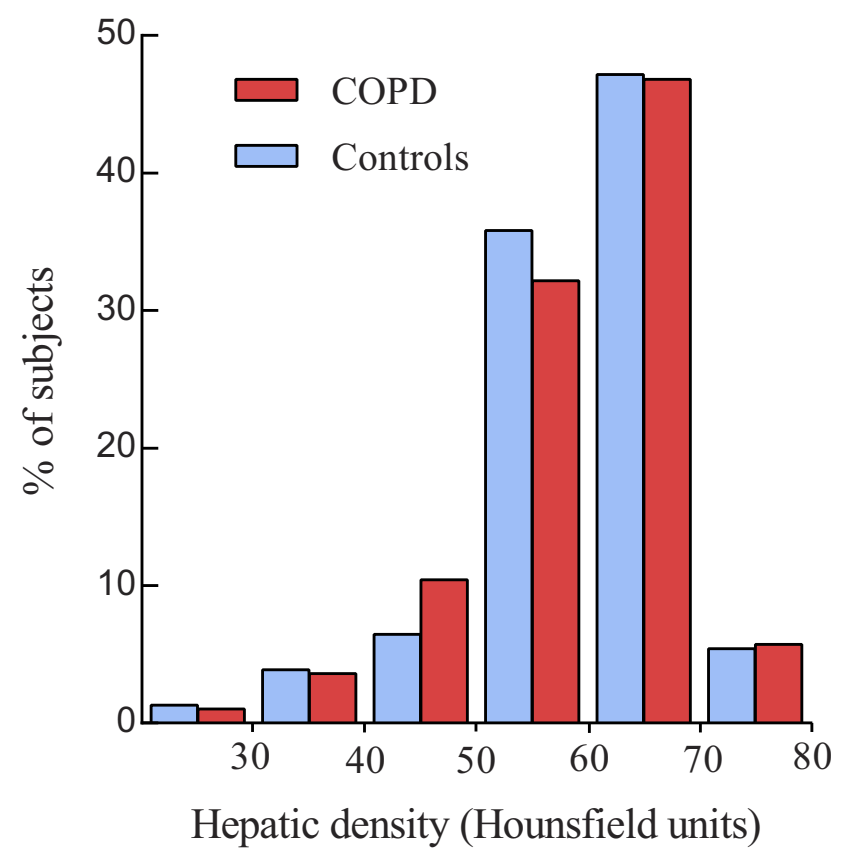

Figure 2 Liver attenuation distribution among patients with COPD and control subjects. $p>0.05$ for all comparisons.

Abbreviation: COPD, chronic obstructive pulmonary disease

the lowest hepatic density quartile (mean attenuation $46 \mathrm{HU}$ ) resulted in an unadjusted $\mathrm{CAD}$ OR=1.71 (95\% CI 1.22 to 2.40), diabetes $\mathrm{OR}=2.96$ (95\% CI 1.753 to 5.007), heart failure $\mathrm{OR}=1.77$ (95\% CI 0.95 to 3.27$)$, hypertension $\mathrm{OR}=1.58(95 \%$ CI 1.17 to 2.14 ) and stroke $\mathrm{OR}=2.07$ (95\% CI 1.02 to 4.21 ). With age and sex adjustment, the association remains significant with $\mathrm{CAD}\left(\mathrm{OR}_{\mathrm{a}}=1.59,95 \%\right.$ CI 1.12 to 2.24$)$, diabetes $\mathrm{OR}=2.80$ (95\% CI 1.64 to 4.77$)$, hypertension $\mathrm{OR}=1.66(95 \%$ CI 1.22 to 2.25$)$ and stroke $\left(\mathrm{OR}_{\mathrm{a}}=2.20,95 \%\right.$ CI 1.07 to 4.50$)$. With age, sex and BMI adjustment, only stroke remained associated with low hepatic density $\left(\mathrm{OR}_{\mathrm{ab}}=2.35,95 \% \mathrm{CI}\right.$ 1.11 to 4.98 ) (Figure 3, Supplementary Table S1). In subgroup analysis by sex, an increased risk for all cardiovascular comorbidities was observed in women (Supplementary Tables S2 and S3).

Among inflammatory markers, interleukin-6 and C Reactive Protein (CRP) were significantly higher in quartile 1 compared to quartile 4 , with a clear doseresponse effect (CRP and IL6 significantly decreasing with increase in hepatic density) (Figure 4). Similar conclusion was reached when the analysis was stratified based on BMI (data not shown).

\section{Discussion}

Despite the potential two-way relationship between COPD and liver steatosis due to chronic low-grade inflammation, 
Table 2 Characteristics of COPD Patients by Liver Attenuation Quartile

\begin{tabular}{|c|c|c|c|c|c|}
\hline & $\begin{array}{l}\text { Quartile I } \\
{[<54.6 \mathrm{HU}]} \\
(n=386)\end{array}$ & $\begin{array}{l}\text { Quartile } 2 \\
\text { [54.6 to } 60.4 \mathrm{HU}] \\
(n=391)\end{array}$ & $\begin{array}{l}\text { Quartile } 3 \\
{[60.4 \text { to } 64.9 \mathrm{HU}]} \\
(n=389)\end{array}$ & $\begin{array}{l}\text { Quartile } 4 \\
{[>64.9 \mathrm{HU}]} \\
(n=388)\end{array}$ & $p$ value $^{\dagger}$ \\
\hline Liver attenuation (HU) & $46.05(0.40)$ & $57.90(0.08)$ & $62.64(0.07)$ & $68.32(0.16)$ & $<0.001$ \\
\hline $\begin{array}{l}\text { Demographics } \\
\text { Age } \\
\text { Sex (\% male) } \\
\text { BMI } \\
\text { Current smokers (\%) } \\
\text { Pack-year }\end{array}$ & $\begin{array}{l}63.8(0.4) \\
270(69.9) \\
28.6(0.3) \\
131(33.9) \\
52(2)\end{array}$ & $\begin{array}{l}64.2(0.3) \\
266(68.0) \\
26.2(0.3) \\
133(34.0) \\
48(1)\end{array}$ & $\begin{array}{l}63.0(0.4) \\
210(53.9) \\
25.0(0.2) \\
147(37.8) \\
47(1)\end{array}$ & $\begin{array}{l}63.2(0.4) \\
202(52.1) \\
24.4(0.2) \\
163(42) \\
47(1)\end{array}$ & $\begin{array}{l}0.07 \\
<0.001 \\
<0.001 \\
0.06 \\
0.04\end{array}$ \\
\hline $\begin{array}{l}\text { Pulmonary function } \\
\text { FEVI (\% pred) } \\
\text { FVC (L) } \\
\text { FEVI/FVC } \\
\text { GOLD stage } \\
\text { 2, n (\%) } \\
3, n(\%) \\
4, n(\%)\end{array}$ & $\begin{array}{l}44.8(0.8) \\
2.88(0.04) \\
0.45(0.01) \\
176(45,6) \\
160(41,5) \\
50(13,0)\end{array}$ & $\begin{array}{l}42.9(0.8) \\
2.85(0.05) \\
0.43(0.01) \\
161(41,2) \\
169(43,2) \\
61(15,6)\end{array}$ & $\begin{array}{l}42.5(0.7) \\
2.68(0.04) \\
0.43(0.01) \\
156(40,1) \\
179(46,0) \\
54(13,9)\end{array}$ & $\begin{array}{l}44.0(0.8) \\
2.66(0.04) \\
0.44(0.01) \\
170(43,8) \\
167(43,0) \\
51(13,1)\end{array}$ & $\begin{array}{l}0.13 \\
<0.001 \\
0.06 \\
0.69\end{array}$ \\
\hline $\begin{array}{l}\text { Health status and functional tests } \\
\text { SGRQ score } \\
\text { mMRC score } \\
6 M W T(m)\end{array}$ & $\begin{array}{l}49(I) \\
1.6(0.1) \\
36 I(6)\end{array}$ & $\begin{array}{l}49(1) \\
1.7(0.1) \\
375(7)\end{array}$ & $\begin{array}{l}49(1) \\
1.6(0.1) \\
384(6)\end{array}$ & $\begin{array}{l}50(1) \\
1.7(0.1) \\
370(6)\end{array}$ & $\begin{array}{l}0.60 \\
0.64 \\
0.08\end{array}$ \\
\hline $\begin{array}{l}\text { Baseline comorbidities } \\
\text { Hypertension, n (\%) } \\
\text { Diabetes, n (\%) } \\
\text { Coronary artery disease, n (\%) } \\
\text { Heart failure, n (\%) } \\
\text { Stroke, n (\%) }\end{array}$ & $\begin{array}{l}168(43.5) \\
57(14.7) \\
113(29.2) \\
30(7.8) \\
24(6.3)\end{array}$ & $\begin{array}{l}154(39.5) \\
36(9.1) \\
97(24.7) \\
19(4.8) \\
11(2.9)\end{array}$ & $\begin{array}{l}150(37.6) \\
26(6.6) \\
77(19.4) \\
23(5.9) \\
12(2.9)\end{array}$ & $\begin{array}{l}127(32.7) \\
21(5.5) \\
75(19.4) \\
18(4.6) \\
12(3.2)\end{array}$ & $\begin{array}{l}0.03 \\
<0.001 \\
<0.01 \\
0.21 \\
0.03\end{array}$ \\
\hline $\begin{array}{l}\text { Follow-up } \\
\text { Death, } \mathrm{n}(\%) \\
\text { Exacerbation rate ( } \mathrm{n} \text { by year) }\end{array}$ & $\begin{array}{l}135(35) \\
1.13\end{array}$ & $\begin{array}{l}160(4 I) \\
I .23\end{array}$ & $\begin{array}{l}123(3 \mathrm{I}) \\
\mathrm{I} .37\end{array}$ & $\begin{array}{l}124(32) \\
1.33\end{array}$ & $\begin{array}{l}0.61 \\
0.04\end{array}$ \\
\hline
\end{tabular}

Notes: Values are expressed with mean \pm SE unless stated otherwise. ${ }^{\dagger} p$-value for $\mathrm{Chi}^{2}$ or ANOVA. Significant $p$-values are shown in bold.

Abbreviations: BMI, body mass index; FEV , forced expiratory volume in I s; FVC, forced vital capacity; SGRQ, St-George Respiratory Questionnaire; mMRC, modified Medical Research Council Dyspnea Scale; 6MWT, 6-min walking test.

intermittent hypoxia and induced adipokines, ${ }^{24,25}$ few data are available to draw an epidemiologic picture of liver steatosis in this population. In a previous study, ${ }^{26}$ we reported that the liver fibrosis stage of non-alcoholic fatty liver disease, but not steatosis, is an independent factor of cardiovascular morbidity in COPD, in line with results in the general population. ${ }^{27,28}$ The present study is the first large multinational COPD cohort with controls to report liver density prevalence. The ECLIPSE data show a similar liver density distribution between COPD and controls. Our results are at variance with previous studies where the prevalence of steatosis ranging from $30 \%$ to $41 \%$ was reported in $\mathrm{COPD}^{24,25}$ and found to be higher than the reported $5 \%$ to $20 \%$ prevalence in the general population. ${ }^{17,29,30}$ These discrepancies are likely related to the use of different diagnostic tools across studies, including biological scores and transient elastography ${ }^{31}$ which have the ability to detect milder fatty infiltration compared to CT scan.

Although CT-scan has its limitations in the assessment of fatty liver disease, ${ }^{32}$ this modality has the advantage of being widely available in pulmonary patients and nevertheless provides a reliable assessment of severe steatosis when liver density is $<40 \mathrm{HU}^{32}$ Furthermore, our purpose was to assess the relevance of this surrogate marker for cardiovascular comorbidities in COPD, which are the main known complications of fatty liver disorders. ${ }^{8,9} \mathrm{CT}$ is also a less invasive alternative to liver biopsy, the gold 


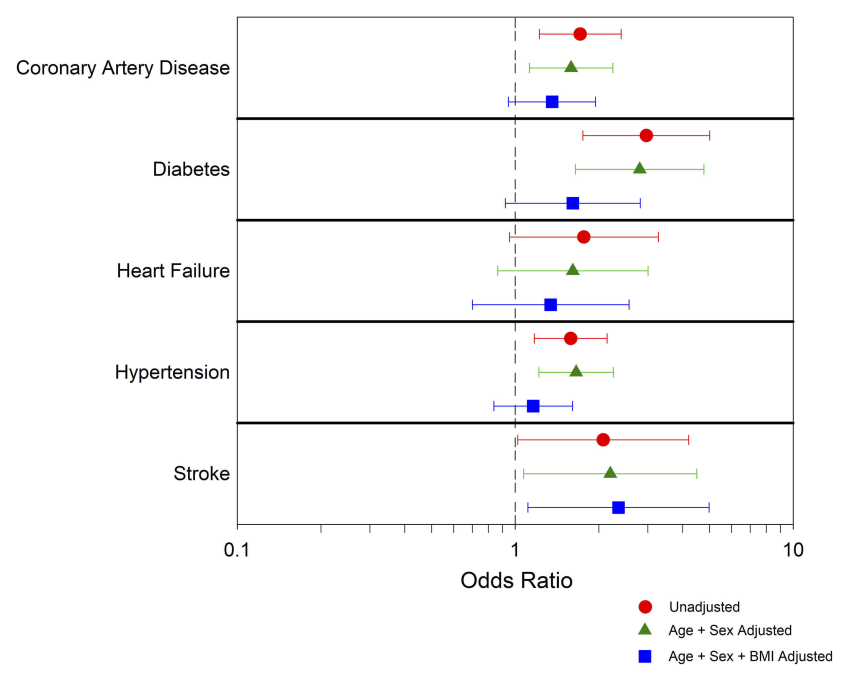

Figure 3 Unadjusted and adjusted odds ratios to present cardiovascular comorbidity in the lowest liver density quartile vs the highest liver density quartile.

standard to diagnose FLD, which is a costly procedure, ${ }^{33}$ prone to minor side-effects such as pain, or more severe complications, including a risk of death of $0.03 \%{ }^{34}$ Moreover, intra and interobserver variabilities exist in the quantification of FLD from a biopsy. ${ }^{35}$ Noninvasive tests (including biological scores and imaging) are cheaper, more easily repeatable, and lead to less interobserver variability, severe adverse events, refusal and bias than biopsy. ${ }^{34}$

Using imaging data already available to the clinicians, screening for FLD could be performed in several patients with COPD. There are currently two methods to assess liver density from a CT scan. In the present investigation, we measured the mean organ attenuation with standardized segmentation which is more complex compared to the multiple region of interest (ROI) methods, ${ }^{17}$ but encompasses a larger area of evaluation which may improve the assessment in case of focal fatty infiltration. ${ }^{36,37}$ In our experience, there is little variation between these techniques as long as they are performed on non-enhanced $\mathrm{CT}^{17}$ We thus recommend the ROI method in clinical practice, mostly because it is less time-consuming than calculating liver attenuation with standardized segmentation and available with current commercial software.

Sexual dimorphism concerns both NAFLD and cardiovascular comorbidities, ${ }^{38,39}$ and hormonal modulation is a key element to understand variations in risk by age and sex. ${ }^{40,41}$ Premenopausal women seem to be protected from developing high levels of NAFLD, while ovarian senescence appears to be associated with severe steatosis and fibrosing NASH. Due to an age $>40$ yo in the COPD population, we could expect more or equal risk of steatosis in women than men. In ECLIPSE, women were less frequently exhibiting low liver density (steatosis), but low liver density in women resulted in stronger association with cardiovascular comorbidities than in men.

Among its potential limitations, the ECLIPSE study did not prospectively assess alcohol consumption, which prevents us from differentiating between FLD and Nonalcoholic fatty liver disease (NAFLD) or to suggest a precise origin for steatosis. However, this limitation should not question the link that we found between liver density with cardiovascular comorbidities because hepatic steatosis leads to worse cardiovascular status, irrespective of the underlying etiology. ${ }^{42}$ In the same way, we were not able to test the effect of some medications associated both with cardiovascular outcomes and fatty liver infiltration, like amiodarone.

Recent data showed that more advanced forms of NAFLD, namely fibrosis rather than steatosis are associated with cardiovascular events. ${ }^{26-28}$ Unfortunately, in the ECLIPSE cohort, no evaluation of liver fibrosis is available, and biological data do not include transaminases, which makes the evaluation by non-invasive NAFLD scores impossible.

The short follow-up of this cohort (3 years) also prevents us from considering the impact of hepatic density on prospective cardiovascular events, due to the limited number of such events during the study period. Finally, the representativeness of the ECLIPSE cohort in relation to the different COPD phenotypes is questionable. Previous studies have tried to identify different phenotypes of COPD patients: frequent exacerbators; ${ }^{20,43}$ eosinophilic patients and asthma-COPD overlap syndrome; ${ }^{44,45}$ and patients with severe airflow limitation at the opposite of those with milder airflow limitation but with obesity and cardiovascular comorbidities. ${ }^{46}$ This last phenotype is the most likely to present both hepatic and cardiovascular comorbidities. Interestingly, in ECLIPSE, patients with GOLD 2 or 3 COPD and a body mass index $>30 \mathrm{~kg} / \mathrm{m}^{2}$ only represented $17 \%(266 / 1554)$ of COPD patients, which could appear low in an occidental population. $6,47,48$

\section{Conclusion}

The present data indicate that a low liver density emerged as a predictor of cardiovascular comorbidities, particularly stroke, in COPD. Although we cannot conclude definitively on the clinical implications of liver steatosis in 

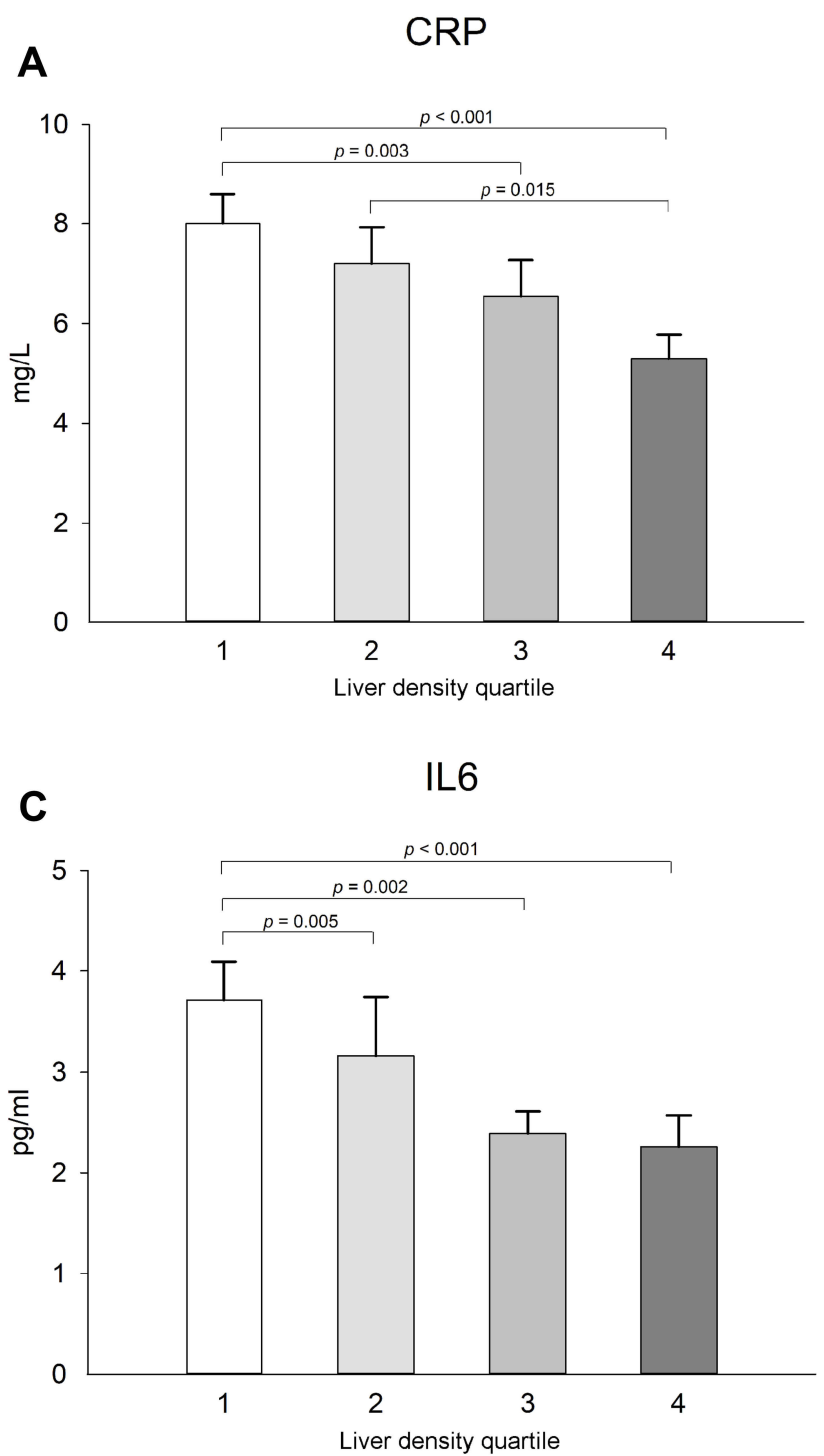

Fibrinogen

B

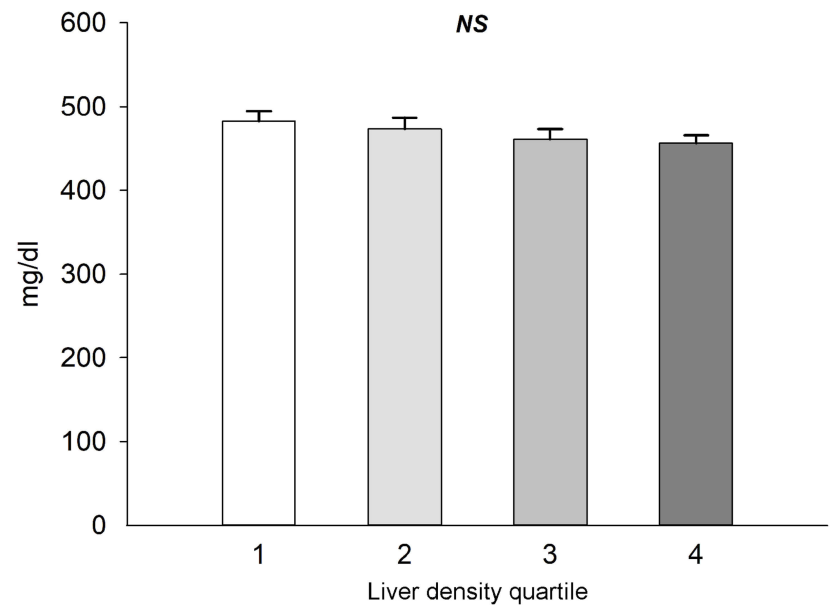

TNF $\alpha$

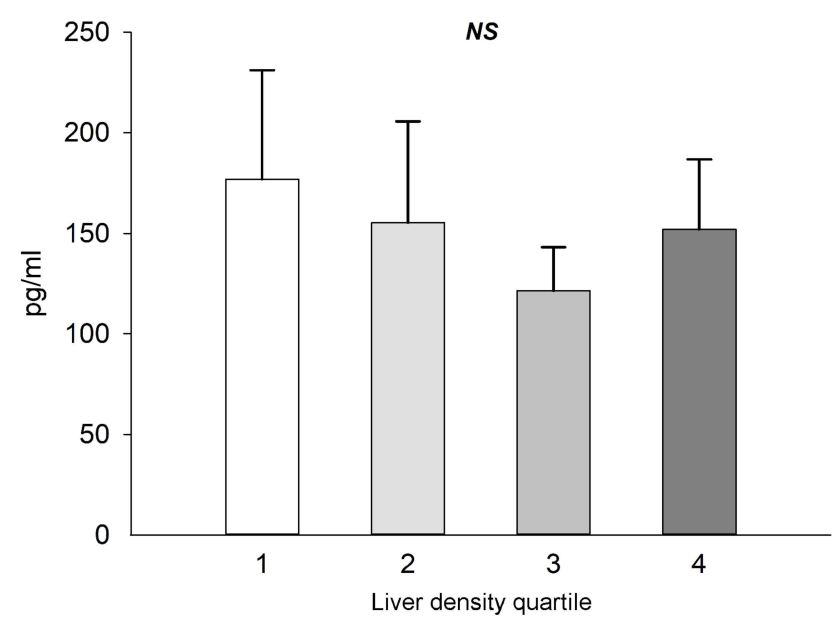

Figure 4 Inflammatory marker levels showing differences according to liver attenuation groups (A-D). Values are expressed with mean \pm standard errors. I is the group with the lowest liver attenuation and 4 the group with the greatest liver attenuation. $p$-value for ANCOVA corrected for age, sex, Body Mass Index and smoking status. Abbreviations: CRP, C-reactive protein; IL6, and interleukin-6.

COPD, this comorbidity is likely relevant considering its association with chronic liver disease and metabolic comorbidities such as insulin resistance, ectopic fat accumulation, and lipid abnormalities.

\section{Abbreviations}

CAD, Coronary Disease; COPD, Chronic Obstructive Pulmonary Disease; CRP, C Reactive Protein; CT, Computed Tomography; ECLIPSE, Evaluation of COPD Longitudinally to Identify Predictive Surrogate Endpoints; FLD, Fatty Liver Disease; GOLD, Global Initiative in Chronic Obstructive Lung Disease; HU, Hounsfield Unit; NAFLD, Nonalcoholic Fatty Liver Disease; OR, Odds Ratio.

\section{Ethics Approval and Informed Consent}

The study is being conducted in accordance with the Declaration of Helsinki and Good Clinical Practice guidelines, and has been approved by the relevant ethics and review boards at the participating centres. All patients provided written informed consent. The ECLIPSE steering and scientific committees approved the protocol for this substudy.

\section{Data Sharing Statement}

The data that support the findings of this study are available from the corresponding author with the permission of the ECLIPSE Collaborative Research Group. 


\section{Acknowledgments}

The authors thank Véronic Tremblay for the body composition analysis platform of the Institut Universitaire de Cardiologie et de Pneumologie de Québec for ensuring standardization of the CT image analyses. They also thank all the subjects, investigators and study site staff who participated in ECLIPSE.

\section{Author Contributions}

All authors contributed toward data analysis, drafting and revising the paper, gave final approval of the version to be published and agree to be accountable for all aspects of the work. The corresponding author had full access to all the data in the study and had final responsibility for the decision to submit for publication.

\section{Funding}

The ECLIPSE study was funded by GlaxoSmithKline (GSK). GSK had no role in the design of the study, analysis, interpretation of results, writing of the article or approval of the article. DV was a recipient of research fellowship grants from the Fonds de la Recherche Québec - Santé, from Institut Universitaire de Cardiologie et de Pneumologie de Québec-Université Laval and from the Agir pour les maladies Chroniques foundation. J-PD is the scientific director of the International Chair on Cardiometabolic Risk, which is based at the Faculty of Medicine, Université Laval. FM holds a GSK/Canadian Institute of Health Research (CIHR) Research Chair on COPD at Université Laval.

\section{Disclosure}

MM, NA and IV have no conflicts of interest to declare. DV reports research grants from Astra Zeneca outside the submitted work. JPD reports personal fees from Abbott Laboratories, AstraZeneca, Sanofi, GSK, Torrent Pharmaceuticals Ltd., Merck and Pfizer Canada Inc., outside the submitted work. HOC reports personal fees and grants from GSK during the conduct of the original ECLIPSE study and no other conflicts during the present study. JLP reports a grant from a consortium of homecare providers (ADIR assistance, Agiradom, IPS, ISIS Medical, LINDE, LVL Medical, SOS Oxygen and Vitalaire) and CPAP companies (Bréas, Philips, Resmed and Sefam), grants from Air Liquide Foundation, Astra-Zeneca, Mutualia, Philips, RESMED, Fisher and Paykel, and personal fees from JAZZ, ITAMAR, Perimetre, Philips, Fisher and Paykel, RESMED, AstraZeneca, SEFAM, Agiradom, ELIA and Teva outside the submitted work. FM reports grants and personal fees from Boehringer Ingelheim and GSK, grants from Nycomed and AstraZeneca, and grants and personal fees from Novartis and Grifols outside the submitted work. All fees are pooled with other revenues of the group of pulmonologists to which FM is a member and then shared among members of the group. The authors report no other conflicts of interest in this work.

\section{References}

1. Lee -CT-C, Mao I-C, Lin C-H, Lin S-H, Hsieh M-C. Chronic obstructive pulmonary disease: a risk factor for type 2 diabetes: a nationwide population-based study. Eur J Clin Invest. 2013;43 (11):1113-1119. doi:10.1111/eci.12147

2. Onishi K. Total management of chronic obstructive pulmonary disease (COPD) as an independent risk factor for cardiovascular disease $J$ Cardiol. 2017;70(2):128-134. doi:10.1016/j.jjcc.2017.03.001

3. Pistelli R, Lange P, Miller DL. Determinants of prognosis of COPD in the elderly: mucus hypersecretion, infections, cardiovascular comorbidity. Eur Respir J Suppl. 2003;40:10s-14s. doi:10.1183/ 09031936.03.00403403

4. Huiart L, Ernst P, Suissa S. Cardiovascular morbidity and mortality in COPD. Chest. 2005;128(4):2640-2646. doi:10.1378/chest.128.4.2640

5. Sin DD, Anthonisen NR, Soriano JB, Agusti AG. Mortality in COPD: role of comorbidities. Eur Respir J. 2006;28(6):1245-1257. doi:10.1183/09031936.00133805

6. Wouters EFM. Obesity and metabolic abnormalities in chronic obstructive pulmonary disease. Ann Am Thorac Soc. 2017;14(Supplement_5): S389-S394. doi:10.1513/AnnalsATS.201705-371AW

7. Reccia I, Kumar J, Akladios C, et al. Non-alcoholic fatty liver disease: a sign of systemic disease. Metab Clin Exp. 2017;72:94-108. doi:10.1016/j.metabol.2017.04.011

8. Ballestri S, Lonardo A, Bonapace S, Byrne CD, Loria P, Targher G. Risk of cardiovascular, cardiac and arrhythmic complications in patients with non-alcoholic fatty liver disease. World $J$ Gastroenterol. 2014;20 (7):1724-1745. doi:10.3748/wjg.v20.i7.1724

9. Liu H, Lu H-Y. Nonalcoholic fatty liver disease and cardiovascular disease. World J Gastroenterol. 2014;20(26):8407-8415. doi:10.3748/ wjg.v20.i26.8407

10. Perazzo H, Poynard T, Dufour J-F. The interactions of nonalcoholic fatty liver disease and cardiovascular diseases. Clin Liver Dis. 2014;18(1):233-248. doi:10.1016/j.cld.2013.09.014

11. Ballestri S, Nascimbeni F, Romagnoli D, Lonardo A. The independent predictors of non-alcoholic steatohepatitis and its individual histological features.: insulin resistance, serum uric acid, metabolic syndrome, alanine aminotransferase and serum total cholesterol are a clue to pathogenesis and candidate targets for treatment. Hepatol Res. 2016;46(11):1074-1087. doi:10.1111/hepr.12656

12. van den Borst B, Gosker HR, Schols AMWJ. Central fat and peripheral muscle: partners in crime in chronic obstructive pulmonary disease. $\mathrm{Am}$ J Respir Crit Care Med. 2013;187(1):8-13. doi:10.1164/rccm.201208$1441 \mathrm{OE}$

13. Minville C, Hilleret M-N, Tamisier R, et al. Nonalcoholic fatty liver disease, nocturnal hypoxia, and endothelial function in patients with sleep apnea. Chest. 2014;145(3):525-533. doi:10.1378/chest.13-0938

14. Aron-Wisnewsky J, Clement K, J-L P. Nonalcoholic fatty liver disease and obstructive sleep apnea. Metab Clin Exp. 2016;65 (8):1124-1135. doi:10.1016/j.metabol.2016.05.004

15. Nascimbeni F, Ballestri S, Machado MV, et al. Clinical relevance of liver histopathology and different histological classifications of NASH in adults. Expert Rev Gastroenterol Hepatol. 2018;12 (4):351-367. doi:10.1080/17474124.2018.1415756 
16. Park SH, Kim PN, Kim KW, et al. Macrovesicular hepatic steatosis in living liver donors: use of $\mathrm{CT}$ for quantitative and qualitative assessment. Radiology. 2006;239(1):105-112. doi:10.1148/ radiol.2391050361

17. Kodama Y, Ng CS, Wu TT, et al. Comparison of CT methods for determining the fat content of the liver. AJR Am J Roentgenol. 2007;188(5):1307-1312. doi:10.2214/AJR.06.0992

18. Boyce CJ, Pickhardt PJ, Kim DH, et al. Hepatic steatosis (fatty liver disease) in asymptomatic adults identified by unenhanced low-dose CT. AJR Am J Roentgenol. 2010;194(3):623-628. doi:10.2214/ AJR.09.2590

19. Vestbo J, Anderson W, Coxson HO, et al. Evaluation of COPD longitudinally to identify predictive surrogate end-points (ECLIPSE). Eur Respir J. 2008;31(4):869-873. doi:10.1183/09031936.00111707

20. Agusti A, Calverley PMA, Celli B, et al. Characterisation of COPD heterogeneity in the ECLIPSE cohort. Respir Res. 2010;11:122. doi:10.1186/1465-9921-11-122

21. Vestbo J, Edwards LD, Scanlon PD, et al. Changes in forced expiratory volume in 1 second over time in COPD. N Engl J Med. 2011;365 (13):1184-1192. doi:10.1056/NEJMoa1105482

22. Davidson LE, Kuk JL, Church TS, Ross R. Protocol for measurement of liver fat by computed tomography. J Appl Physiol. 2006;100 (3):864-868. doi:10.1152/japplphysiol.00986.2005

23. Martin M, Almeras N, Després J-P, et al. Ectopic fat accumulation in patients with COPD: an ECLIPSE substudy. Int J Chron Obstruct Pulmon Dis. 2017;12:451-460. doi:10.2147/COPD.S124750

24. Moon SW, Kim SY, Jung JY, et al. Relationship between obstructive lung disease and non-alcoholic fatty liver disease in the Korean population: korea National Health and Nutrition Examination Survey, 2007-2010. Int J Chron Obstruct Pulmon Dis. 2018;13:2603-2611. doi:10.2147/COPD.S166902

25. Viglino D, Jullian-Desayes I, Minoves M, et al. Nonalcoholic fatty liver disease in chronic obstructive pulmonary disease. Eur Respir J. 2017;49:6. doi:10.1183/13993003.01923-2016

26. Viglino D, Plazanet A, Bailly S, et al. Impact of non-alcoholic fatty liver disease on long-term cardiovascular events and death in Chronic Obstructive Pulmonary Disease. Sci Rep. 2018;8(1):16559. doi:10.1038/s41598-018-34988-2

27. Angulo P, Kleiner DE, Dam-Larsen S, et al. Liver fibrosis, but no other histologic features, is associated with long-term outcomes of patients with nonalcoholic fatty liver disease. Gastroenterology. 2015;149(2):389-397.e10. doi:10.1053/j.gastro.2015.04.043

28. Targher G, Byrne CD, Lonardo A, Zoppini G, Barbui C. Nonalcoholic fatty liver disease and risk of incident cardiovascular disease: a meta-analysis. J Hepatol. 2016;65(3):589-600. doi:10.1016/j. jhep.2016.05.013

29. Speliotes EK, Massaro JM, Hoffmann U, et al. Fatty liver is associated with dyslipidemia and dysglycemia independent of visceral fat: the Framingham Heart Study. Hepatology. 2010;51(6):1979-1987. doi:10.1002/hep.23593

30. Loomba R, Sanyal AJ. The global NAFLD epidemic. Nat Rev Gastroenterol Hepatol. 2013;10(11):686-690. doi:10.1038/ nrgastro.2013.171

31. Tapper EB, Loomba R. Noninvasive imaging biomarker assessment of liver fibrosis by elastography in NAFLD. Nat Rev Gastroenterol Hepatol. 2018;15(5):274-282. doi:10.1038/nrgastro.2018.10

32. Sumida Y, Nakajima A, Itoh Y. Limitations of liver biopsy and non-invasive diagnostic tests for the diagnosis of nonalcoholic fatty liver disease/nonalcoholic steatohepatitis. World J Gastroenterol. 2014;20(2):475-485. doi:10.3748/wjg.v20.i2.475
33. Tapper EB, Sengupta N, Hunink MGM, Afdhal NH, Lai M. Costeffective evaluation of nonalcoholic fatty liver disease with NAFLD fibrosis score and vibration controlled transient elastography. $\mathrm{Am}$ J Gastroenterol. 2015;110(9):1298-1304. doi:10.1038/ajg.2015.241

34. Munteanu M, Ratziu V, Morra R, Messous D, Imbert-Bismut F, Poynard T. Noninvasive biomarkers for the screening of fibrosis, steatosis and steatohepatitis in patients with metabolic risk factors: fibroTest-FibroMax experience. J Gastrointestin Liver Dis. 2008;17 (2):187-191.

35. Hashimoto E, Taniai M, Tokushige K. Characteristics and diagnosis of NAFLD/NASH. J Gastroenterol Hepatol. 2013;28(Suppl 4):64-70. doi:10.1111/jgh.12271

36. Halvorsen RA, Korobkin M, Ram PC, Thompson WM. CT appearance of focal fatty infiltration of the liver. AJR Am J Roentgenol. 1982;139(2):277-281. doi:10.2214/ajr.139.2.277

37. Kammen BF, Pacharn P, Thoeni RF, et al. Focal fatty infiltration of the liver: analysis of prevalence and CT findings in children and young adults. AJR Am J Roentgenol. 2001;177(5):1035-1039. doi:10.2214/ajr.177.5.1771035

38. Ballestri S, Nascimbeni F, Baldelli E, Marrazzo A, Romagnoli D, Lonardo A. NAFLD as a sexual dimorphic disease: role of gender and reproductive status in the development and progression of nonalcoholic fatty liver disease and inherent cardiovascular risk. $A d v$ Ther. 2017;34(6):1291-1326. doi:10.1007/s12325-017-0556-1

39. Du T, Sun X, Yuan G, et al. Sex differences in the impact of nonalcoholic fatty liver disease on cardiovascular risk factors. Nutr Metab Cardiovasc Dis. 2017;27(1):63-69. doi:10.1016/j.numecd.2016.10.004

40. Jaruvongvanich V, Sanguankeo A, Riangwiwat T, Testosterone US. Sex hormone-binding globulin and nonalcoholic fatty liver disease: a systematic review and meta-analysis. Ann Hepatol. 2017;16 (3):382-394. doi:10.5604/16652681.1235481

41. Palmisano BT, Zhu L, Stafford JM. Role of estrogens in the regulation of liver lipid metabolism. Adv Exp Med Biol. 2017;1043:227-256. doi:10.1007/978-3-319-70178-3_12

42. Toshikuni N, Tsutsumi M, Arisawa T. Clinical differences between alcoholic liver disease and nonalcoholic fatty liver disease. World J Gastroenterol. 2014;20(26):8393-8406. doi:10.3748/wjg.v20.i26.8393

43. Donaldson GC, Seemungal TA, Bhowmik RA, Wedzicha JA. Relationship between exacerbation frequency and lung function decline in chronic obstructive pulmonary disease. Thorax. 2002;57 (10):847-852. doi:10.1136/thorax.57.10.847

44. Bafadhel M, McKenna S, Terry S, et al. Acute exacerbations of chronic obstructive pulmonary disease: identification of biologic clusters and their biomarkers. Am J Respir Crit Care Med. 2011;184(6):662-671. doi:10.1164/rccm.201104-0597OC

45. Chou K-T, Su K-C, Huang S-F, et al. Exhaled nitric oxide predicts eosinophilic airway inflammation in COPD. Lung. 2014;192 (4):499-504. doi:10.1007/s00408-014-9591-8

46. Garcia-Aymerich J, Gómez FP, Benet M, et al. Identification and prospective validation of clinically relevant chronic obstructive pulmonary disease (COPD) subtypes. Thorax. 2011;66(5):430-437. doi:10.1136/thx.2010.154484

47. Vozoris NT, O'Donnell DE. Prevalence, risk factors, activity limitation and health care utilization of an obese, population-based sample with chronic obstructive pulmonary disease. Can Respir J. 2012;19 (3):e18-24. doi:10.1155/2012/732618

48. García-Rio F, Soriano JB, Miravitlles M, et al. Impact of obesity on the clinical profile of a population-based sample with chronic obstructive pulmonary disease. PLOS ONE. 2014;9(8):e105220. doi:10.1371/journal.pone. 0105220 


\section{Publish your work in this journal}

The International Journal of COPD is an international, peer-reviewed journal of therapeutics and pharmacology focusing on concise rapid reporting of clinical studies and reviews in COPD. Special focus is given to the pathophysiological processes underlying the disease, intervention programs, patient focused education, and self management protocols. This journal is indexed on PubMed Central, MedLine and CAS. The manuscript management system is completely online and includes a very quick and fair peer-review system, which is all easy to use. Visit http://www.dovepress.com/testimonials.php to read real quotes from published authors. 